\title{
Research on the Talent Training Mode and Path in Continuing Higher Education Based on Digital Reform
}

\author{
Jiamin Huang (Corresponding author) \\ Scientific Research Office, Zhejiang Open University, \\ Hangzhou, Zhejiang, 310012, China
}

Received: December 16, 2021 Accepted: January 17, 2022 Published: January 21, 2022

doi: $10.5296 /$ jsss.v8i2.19487

URL: https://doi.org/10.5296/jsss.v8i2.19487

\begin{abstract}
As the digital reform unfolds at an incredible pace, the continuing higher education faces opportunities to transform and upgrade. Although emerging technologies such as 5G, Internet and artificial intelligence are gaining a foothold in continuing education, the continuing higher education must deal with challenges and issues in education orientation, teaching mode, talent training, etc. There is an urgent need of standardized management, reform and development. This paper aims to establish the accurate orientation and staggered development path for continuing education in colleges and universities on the macro, meso and micro levels. On the macro level, it studies the accurate orientation and staggered development path of continuing education in the digital reform era; on the meso level, it explores the standardized management of continuing higher education and reform measures of digital talent training mode; on the micro level, it discusses how to leverage the advantages in colleges and universities, build role models in digital reform education programs and learning bases, reform the standardized management and talent training mode, and propel the high-quality development of continuing higher education.
\end{abstract}

Keywords: digital reform, continuing higher education, reform and development, path research

\section{Introduction}

The progress in digital reform is motivating the continuing education to go digital as well. Thanks to the new technologies such as big data, artificial intelligence and 5G, distance learning is more accessible, and online learning and lifelong learning are gaining popularity. Time, place or age no longer restricts the learners. Chinese government listed 38 new professions in three batches in 2019 and 2020, of which more than half were related to digital reform. The accelerating digital transformation in traditional industries generates plenty of 
new jobs. By offering the new lifelong learning choice for all, the continuing higher education presents all kinds of education modes to various demographic groups. Facing the great momentum in digital reform, this can be a solution for the uneven development between the technological knowledge build-up and talent pool growth. Nevertheless, there is a big gap between the continuing higher education and digital reform requirements. New challenges and issues in supply-demand relation, teaching practice and talent training remain to be obstacles for the transformation and development. The talent quality and word of mouth of the continuing higher education are largely compromised, thus urgently calling for the standardized management, reform and development.

Against the backdrop of digital reform and development, it is necessary to analyze the status quo, problems and root causes of China's continuing higher education, clarify the orientation and staggered development path on the macro, meso and micro levels and suggest on standardized management and talent training mode reform. These efforts will ensure the teaching quality in continuing higher education, and contribute to the social and economic progress.

\section{Status Quo and Dilemma of Continuing Higher Education in the Digital Reform Era}

\subsection{Digital Continuing Education in Developed Countries}

Human resource is an evolving game in the digital age. European Union, Germany, Denmark and other developed areas have rolled out complete narratives and measures to cultivate talents for the digitally reformed industries, and offered solid practical trainings and professional certification systems accordingly.

The European E-Competence Framework, announced by the European Union in 2005, was the competence criteria for ICT talents that the EU wished to encourage. Considering that over 50\% of European citizens lack digital skills, the eSkills program was launched in 2016. It exhaustively covered the policies, functions and coaching from primary school, middle school, university, on-the-job training, employment and lifelong learning, thus welcomed and promoted by many EU members.

To keep up with the digital era, Germany adopted the first "National Continuing Education Strategy" in 2019 (Duan, 2019), regarded as a milestone for further vocational training in the country. It was a digital reform expanded from the academic education and vocational education to the entire society education, aiming at making continuing education opportunities more transparent and easier to access. Its "Open University" section provided digital continuing education courses with academic degree for the public, which inspired the continuing education initiative in Germany.

Denmark proposed three goals in the ambition to be a front runner in the digital reform: share the benefits of digitalization with all the citizens, enhance productivity in enterprises and meet SME's digital upgrading expectation, and push digital transformation in economy through good digital framework conditions(Le, 2019). In order to boost the digital skills of labors, Denmark prepared flexible and specific adult and continuing education courses to address the corporate need.

The practice of continuing education in developed countries proves that the government 
overall planning is a "wind vane." $(\mathrm{Xu}, 2017)$ The developed countries see the continuing education as an essential impetus for sustainable development and pinpoint it in the national strategy. Therefore, China can learn these experiences, formulate policies to support continuing education, and unlock more potential and fund on continuing education for all the citizens.

\subsection{China's Continuing Higher Education Shows More Value in the Digital Age}

Ushering in the digital reform age, China's continuing higher education faces the critical moment of reform and development. Previously, it is a compensatory education for academic qualifications; today, it is an integral component in the modern education system to support lifelong learning. Such an achievement is incredible.

\section{(1) Universalize higher education for all}

The continuing education for better academic qualification is getting popular in China in the recent decade. The number of enrollments in continuing higher education has enjoyed stable growth for years. According to the 2020 Statistical Bulletin on the Development of National Education, the entrants of adult normal and short-cycle courses exceed 3 million. For web-based normal and short-cycle courses, there are 2.7791 million entrants and 8.4645 million enrollments. The value and social recognition in continuing higher education are steadily enhanced, the policies are supportive, and the demandsare high. As a result, more and more people choose the continuing education for academic qualification and better competitiveness.

\section{(2) Contribute positively to a learning society}

The continuing higher education is flexible and diversified. Academic education types include off-the-job, spare time, correspondence, modern distance, etc., while non-academic education can be organized for the community, seniors, etc. These complementary choices are significant channels for the lifelong education and lifelong learning for all the people.

\section{(3) Unleash the potential in continuing higher education}

The continuing higher education has close connection with industries, firms and society. The collaboration between enterprises and schools and the integration of education with industry generate the most updated talent training information. It also drives the colleges and universities to focus not only on the academic continuing education, but also on the non-academic continuing education and training. Taking Zhejiang Province as an example, its 85 colleges and universities received 211,907 entrants for academic continuing education in 2019 (including 90,729 for normal courses and 121,179 for short-cycle courses). The number of entrants for non-academic continuing education reached 1,998,699 (including 626,189 training opportunities for qualifications or technologies), which almost registered RMB 2.7 billion in revenue. Zhejiang is doing well in terms of the student size and the training income.

\subsection{China's Continuing Higher Education Struggles to Improve}

(1) Re-examine the education orientation 
It is common that Chinese colleges and universities underrate the academic continuing education and compromise the teaching quality. Some even separate the academic continuing education from their talent training, and regard the continuing higher education as a school-run industry or a cash cow for extra revenue. Some continuing education staff exaggerate the teaching quality and mislead in publicity in order to deliver results(Zhu, 2020). They collaborate with private training agencies without considering the school level, discipline competitiveness and student source. Many disputes have been arisen, marring the school's imageand posing risks to safety, stability and integrity.

\section{(2) Strengthen the discipline offering and teaching practice}

Since most continuing higher education rely on the facilities, faculty and cultural resources in the colleges and universities, they tend to borrow the general mode indiscriminately and fail to develop their own education characteristics(He, 2017). Some schools, in their desperate pursuit of the so-called "benefits", set disciplines and expand enrollment without deliberation and fail to show advantages in their discipline offering. Some others simply copy the full-time student training practice when arranging training schemes, setting courses and selecting textbooks, and fail to meet the adult and economic/social need. Particularly, with the trend of digital reform, the misalignment between the continuing education and digital industry severely affect the education outcome.

\section{(3) Innovate the teaching mode}

The digital transformation presents a paradigm shift to learning and teaching for all. The time, space, dimension and method to acquire knowledge will be changed. How to get the students and educators ready for the digital reform and development is of great importance. The continuing education practitioners in colleges and universities should identify education modes that suit local economy(Liu , 2019)and contribute an essential share for the local economy and social advancement.

In the digital reform era, it is of immediate significance to study and explore a practical path to transform and develop the continuing higher education. It is also a critical move to find out whether the continuing higher education can play an active role in the lifelong learning system, facilitate the deep integration of continuing education and information technology and embody the "education for all" concept in the digital era.

\section{Reform and development path of continuing higher education in the digital reform era}

\subsection{Marco Level: Clarify the Orientation of Continuing Higher Education in the Digital Reform Age}

The continuing higher education work should reflect the characteristics of the digital reform era and synchronize with digital reform dynamics and social development need.

(1) Pinpoint the function of continuing higher education in the digital reform era

On the supply side, continuing higher education has toshowcase unique characteristics, share 
the digital know-how and offer more high-end scientific and technological knowledge. On the demand side, continuing higher education must rebuild the value philosophy, reinforce the teaching practice and enhance the brand awareness. Some capable schools must take the weighty task of spreading and training the digital reform knowledge, and intensify the learning and sharing of digital skills in academic education.

\section{(2) Stress the importance of continuing education in colleges and universities}

The continuing education is supposed to raise its status in the school development, be included in the overall school planning and talent training system, and be coordinated with full-time education. As China is building into a learning society, people will come across vocational education, higher education and continuing education sooner or later throughout their lives. The coordination of their relations and developing stages will reinvigorate the continuing education.

\section{(3) Set goals for talent training in continuing higher education}

Continuing higher education is profession-oriented when it comes to talent training. The primary purpose is to fit the national strategy and digital reform needs, improve learners' digital capability and prepare them for the ever-changing social needs. The United States, Japan and Denmark are good examples in designing the open continuing education. They encourage contact and communication with enterprises and social organizations, suit the digital reform needs, and support individual learning based on the features of the adult continuing education.

\section{(4) Advance the staggered development of continuing higher education}

The regular colleges and universities are advised to leverage their advantages, and focus on academic and non-academic education and training on high levels. Higher vocational schools are expected to address the need of technical talents in modern vocational education, and focus on improving the frontline workers' professional ethics, skills and academic qualifications. The open universities (TV universities) are recommended to utilize their system and focus on various education and training for grassroots and rural communities.

\subsection{Meso Level: Work Out the Dilemma of Training Talent in Continuing Higher Education for the Digital Reform}

Digital reform is a critical engine that accelerates the quality, efficiency and dynamics change in the economic and social development. It is necessary to analyze the status quo of continuing higher education thoroughly to work out the dilemma of training talent for the digital reform.

\section{(1) Highlight advantages in discipline offering}

Some schools, in their desperate pursuit of the so-called "benefits", set disciplines and expand enrollment without deliberation. The continuing higher education should proactively adapt to the digital reform market and understand what the digital industry wants. The gap between continuing education and digital corporate training needs to be addressed by 
thorough alignment mechanisms and adequate practices.

\section{(2) Align teaching with market need}

Some schools simply copy the full-time student training practice when arranging training schemes, setting courses and selecting textbooks, and fail to meet the digital reform and development need. The discipline setting and digital reform in continuing higher education should follow the new business forms and new demands, and respond to the adjustment, upgrading and transformation in industrial structures.

\section{(3) Equip teachers with "dual capabilities"}

Some teachers in colleges and universities have not been trained with digital industry education and cannot offer practical teaching. They should be equipped with "dual capabilities", in other words, they should receive more trainings in both theoretical knowledge and digital skills.

\section{(4) Intensify support and services for online learning}

It is necessary to develop resources (e.g. MOOC, micro class), harness emerging technologies (e.g. artificial intelligence, 5G) and organize online teaching, flipped classroom, etc. Teaching methods and means should be tailor-made for each student.

\subsection{Micro Level: Forge a Talent Training Mode that Fits the Digital Reform and Development}

To transform and develop continuing higher education, the colleges and universities must leverage their discipline advantages, major characteristics and mature programs, and build a series of boutique programs on academic continuing education and competitive non-academic education program clusters. The staggered development with unique styles will help to establish continuing education bases that fit the digital reform and train talents that underpin the regional economic and social development.

\section{(1) Foster the mindset: empower the high-quality digital reform with continuing education}

Government, colleges, universities and other stakeholders should pinpoint the continuing education's orientation, and continue to improve the awareness of standardization and its value. Continuing education is more than a compensatory solution. It is a crucial human resource pool for digital reform, thus staggered development should be encouraged. It is necessary to clarify the continuing education's position in the higher education, and the goals of talent training, since digital reform is calling for a great number of new jobs. The continuing higher education is supposed to respond to the digital reform era, serve the social transformation need, and prepare talents for the new vacancies in the digital reform.

(2) Strengthen the standardized management: drive the modernization of governance system and governance ability in continuing higher education

Colleges and universities, as the host of education, take primary responsibilities in all kinds of continuing higher education. To address the governance issues, on the one hand, government should engage deeper and formulate policies and regulations on the continuing 
higher education; on the other hand, schools should take the initiative to standardize the practice in critical steps (e.g. enrollment, examination, charge, diploma).

(3) Reinforce teaching practice: better consolidate the continuing higher education with information technology

In the digital reform age, new technologies such as cloud computing, big data, artificial intelligence and $5 \mathrm{G}$ are expected to be used to intensify the digital campaign of the continuing higher education. Referring to the digital reform requirements, the talent training mode, discipline and courses setting and teaching method need adjustment. Informatization will stimulate innovation in the standardized management of continuing education, and the governance ability of the continuing education team will be elevated across the board.

(4) Coordinate with enterprises: develop an industry-education integration mode in the digital reform era

The schools are expected to follow the government policies and industry updates, understand the planning and trend in digital reform, and analyze the technical development, industrial program and talent need in local areas. Then, discipline setting can be optimized to fit local industry, and experts can be invited to develop an efficient course system. By introducing the enterprises into the schools, students will have access to complementary courses and practices. In the end, amulti-stakeholder (schools, government, enterprises, etc.) integrated system will be built.

\section{Conclusion}

The purpose for the transformation and development of the continuing higher education in the digital reform era is to unleash more open education possibilities. Everybody can learn any time at any place, without any restriction in time, space or demographic group. Education should be more relevant, so that learning scenarios and modes will be diversified and suit each individual; education should be fairer, so that everyone can access premium education platforms and resources; and education should be more sustainable, so that the learning capability will be built and the lifelong education will be highlighted. To find out whether continuing education can play a positive role in the lifelong learning system for all, it makes sense to refer to the digital reform industries and talent training principles, collect the trend on digital transformation in continuing education at home and abroad, analyze the status quo and policy gap in China's continuing higher education, and ultimately explore a practical path to transform and develop the continuing higher education.

\section{Supporting Agencies:}

A Project Supported by Scientific Research Fund of 2021 Zhejiang Provincial Education Department of China "Research on the Talent Training Mode and Path in Continuing Higher Education based on Digital Reform” (Project Number:Y202146823).

This paper is the research result of Zhejiang Open University "312 Talent Training Project"; And also the research result of Zhejiang Radio and Television University 2020 Higher Education and Teaching Reform Project "Research on the Path of Integrated Major and 


\section{Macrothink}

Journal of Social Science Studies

ISSN 2329-9150

2021, Vol. 8, No. 2

Curriculum Construction of Open University under the Modernization Vision Of Education Governance" (Project No: XJG202014).

\section{Conflicts of Interest}

The author declares no conflicts of interest.

\section{References}

Duan, J. H. (2019). Germany Adopted the First "National Continuing Education Strategy" [J]. Journal of World Education, 19, 75.

He, J. (2017). Practical Dilemma and Reform Strategies for the Transformation of Continuing Higher Education. China Adult Education, 6, 119-123.

Le, C. Y., \& Yu, S. (2019). On the Practical Logic of Continuing Education Governance at the University from the Perspective of Collective Action. Journal of Higher Education, 12, $35-41$.

Liu, C. Y., \& Zhang, J. (2019). Brief Discussion on How can Continuing Higher Education Promote Local Economic Development and Social Development. Modern Economic Information, 12, 32-35.

The Agency for Digitization of the Ministry of Finance Put Forward Digital Reform Suggestions to Government. Retrieved from http://www.casisd.cn/zkcg/ydkb/kjzcyzxkb/2017/201709/201709/t20170908_4857637.html

$\mathrm{Xu}$, H. N., \& Wang, W. T. (2017). Comparison of Continuing Education in Developed Countries and its Lessons for China. Adult Education, 10, 87-88.

Zhu, H. X., \& Ma, Y. A. (2020). On Functional Orientation and Strategies of Continuing Education of Research-oriented Universities in China. Vocational and Technical Education, 13, 74-79.

\section{Copyright Disclaimer}

Copyright for this article is retained by the author(s), with first publication rights granted to the journal.

This is an open-access article distributed under the terms and conditions of the Creative Commons Attribution license (http://creativecommons.org/licenses/by/4.0/). 